\title{
Why 'consciousness' means what it does
}

\begin{abstract}
'Consciousness' seems to be both polysemic and ambiguous. Univocalists about consciousness argue that it is not. By drawing upon the history of philosophy and psychology, and some simple technical resources from semantic theory, we gain an account of why 'consciousness' means the various things that it does. Univocalism is shown to be implausible. This is important, for if we accept the univocalist account then we are less likely to subject our thought and talk about the mind to the kind of critical analysis that it needs. The exploration of the semantics of 'consciousness' offered here, by way of contrast, helps to clarify and fine-tune our thought and talk about consciousness and conscious mentality.
\end{abstract}

You are at a conference and a former colleague says: 'I am writing a book on consciousness.' From this isolated remark it is not at all clear just what she is writing her book about. Is it about self-knowledge? Is it about the qualitative nature of experience? Is it about our waking mental life? There is nothing odd about this kind of ambiguity. People have been going on about the ambiguous, polysemic nature of consciousness for a very long time, and they still go on about it today. (Hamilton 1859; Bain 1879; Lewis 1960; Burt 1962; Natsoulas 1978; Wilkes 1988; Allport 1988; Nelkin 1993; Block 1995). Two points of agreement seem to emerge from such reflection. First, 'consciousness' means a number of different things: 'consciousness' is polysemic. Second, there is a risk of misunderstanding or confusing these different notions: 'consciousness' is ambiguous.

Because ‘consciousness' is polysemic and ambiguous contemporary theorists of mind engage in explicit discussion about the kinds of phenomena that ‘consciousness’ denotes (Rosenthal 1997; Tye 1996; Lormand 1996). Given the risk of conflation and confusion there is also a widespread practice of explicitly 
specifying, and differentiating, various species of consciousness. ${ }^{1}$ Theorists need this fine-tuned technical vocabulary because 'consciousness' itself has a number of different meanings that are apt to be conflated.

This proliferation of technical vocabulary poses an obstacle to clear communication within philosophy, and between philosophers and psychologists. Do these different terms refer to different phenomena? Or are some of them merely different terms for one and the same thing? If your colleague says that she is writing a book on 'monitoring consciousness' is that the same thing as 'access consciousness' or 'epistemic consciousness'? One response to the proliferation of notions of consciousness is to argue that there is, contrary to appearances, a unique core notion-this is univocalism about consciousness.

\section{Univocalism}

\subsection{McBride: against polysemy}

Most contemporary theorists of consciousness accept a broad tripartite distinction between state consciousness, creature consciousness, and transitive consciousness. (Rosenthal, 1997; Carruthers, 1996; Block, 1997; Lycan, 1996; Dretske, 1993; VanGulick 1996). We talk of people and animals being conscious (creature consciousness), we talk of their being conscious of something, and of their being conscious that something is the case (transitive consciousness). We can also pose the question of 'what it is for a mental state to be conscious' (Rosenthal 1997, 729). In

\footnotetext{
${ }^{1}$ For example: state consciousness; creature consciousness; phenomenal consciousness; access consciousness; transitive consciousness; intransitive consciousness; monitoring consciousness;
} 
posing such a question we are concerned with state consciousness (Rosenthal 1993, 197; Rosenthal 1997, 729).

McBride (1999) argues that these distinctions, amongst different notions of consciousness, do not correspond to any real distinction in phenomena. McBride is thus primarily concerned one particular way in which 'consciousness' is said to be polysemic: i.e., that 'consciousness' denotes a range of distinct phenomena. McBride argues for a 'Unitary Thesis' whereby 'being in a conscious state, being conscious of something and being conscious to some degree are, rather than distinct mental phenomena, actually bound together in conscious experience' (McBride 1999, 194). This argument rests upon the assumption that 'distinct phenomena can manifest distinctly, i.e., independently' (1999, p. 187). If state consciousness, transitive consciousness and creature consciousness really were distinct then it should be possible for them to be manifest independently of one another. He then draws upon intuitions to the effect that (i) a creature cannot be conscious without that creature having some conscious mental state; (ii) a creature cannot have a conscious mental state without its also being the case that the creature is conscious; (iii) a creature who is conscious of something has a conscious mental state. Such intuitions are meant to establish that each putative species of consciousness cannot, in fact, be manifest in independence of the others.

The assumption that distinct phenomena must be able to manifest themselves distinctly is itself questionable. Suppose we accept that a creature is conscious if and only if it has conscious mental states. All this amounts to is the fact that there is a logical interdependence between two notions: that of a conscious creature or subject, and that of a conscious mental state. However, this logical interdependence does not, 
by itself, rule out the distinctness of state consciousness and creature consciousness as properties. To see that this is so we need simply note that conscious subjects can (and do) have unconscious mental states. Suppose we want to know what the difference between conscious and unconscious mental states consists in. If both kinds of state are states of a conscious subject, it cannot be the subject's consciousness simpliciter which constitutes the difference. Insofar as we can seek to explain the conscious (as opposed to unconscious) status of a mental state, as opposed to the conscious (as opposed to unconscious) status of a subject of mental states, we should admit that state consciousness and creature consciousness denote different properties, even if there is a logical relation between them.

\subsection{Antony: against ambiguity}

Michael V. Antony (2001; 2002) proposes a more subtle, less unitarian, variant of univocalism about consciousness. He accepts that our everyday discourse does indeed deploy different notions of consciousness (e.g., class consciousness; consciousness as the waking state). But, he argues, this is not problematic for psychology or philosophy. After all, no one in their right mind would argue from the true premiss that 'rock' can mean different things in everyday English (a type of music; large mass of stone; a type of sweet, etc), that geologists run the risk of conflating these notions. Everyday language abounds with homonyms but competent adult speakers are well able to draw upon their background knowledge and understanding of the context of utterance to determine a correct interpretation of what the speaker means.

nonphenomenal consciousness; minimal consciousness; perceptual consciousness, to name but a few. 
Homonymy is not the same as polysemy. Homonymous terms need have little, if anything, in common at the semantic level. Polysemic terms, by way of contrast, seem to have something in common at the semantic level. Identifying the precise distinction between homonymy and polysemy is not easy. Antony seeks to show that, at least with regard to contemporary philosophical and psychological theorising about consciousness we can view the many putatively distinct notions of consciousness as having a single semantic notion at their core. Antony thus accepts that 'consciousness' is used in a variety of different ways. What he seeks to show is that this variety of uses can be explained in terms of the 'highlighting' of this or that feature of some widely accepted core notion of consciousness. More specifically, the superficial variability in notions of consciousness is to be explained in terms of semantic modulation (Cruse 1986). Semantic modulation involves semantic variability relative to a fixed meaning. For example, the lexical term 'good' has a different sense in 'good car'; 'good child'; 'good riddance', but there is something in common between the different uses of 'good', unlike the case of homonyms like 'rock' (meaning music) and 'rock' (meaning large mass of stone).

Antony argues that we can understand the various senses of 'consciousness' within contemporary theorising about the mind as modulations of a single core sense of 'consciousness'. This univocalist strategy is both similar to, but distinct from, McBride’s. McBride’s 'Unitary Thesis' sought to place one particular notion of consciousness as the core notion: 'the main thrust of the Unitary Thesis was plain, consciousness is about conscious experience' (1999, 184). Antony's account is univocalist but less unitarian. In Antony's view, the core, general notion of consciousness is a complex, many-stranded one. 
Corresponding to the word 'consciousness' we have a rich conception of a complex and multi-faceted mental phenomenon. This phenomenon appears to comprise (something like) states and events with phenomenal or qualitative aspects that are temporally located, that enter into part-whole relations, that are related to intentional features of the mind, that enter into causal relations with one another and with unconscious mental states and events, and so on. This complex phenomenon seems intimately linked to wakefulness, attentiveness, and capacities for "inner reflection"-though perhaps none of those are necessary. Something like that, and much more, goes to make up our complex conception or picture of consciousness. (2001, 28-29)

Given that theorists' interests and explanatory concerns vary, and given the complexity of the core notion of consciousness, it is not surprising that 'different features of the phenomenon on different occasions will be thrown into relief or emphasized-sometimes phenomenal features, sometimes functional or cognitive ones, etc. - while others are suppressed' $(2001,29)$. So, the basic idea is that (a) there is some notion of consciousness that contemporary theorists are already all committed to; (b) we can explain away polysemy via semantic modulation of this core notion; (c) given (a) metalinguistic reflection about 'consciousness' and its senses is redundant and apt to mislead (Antony 2001; 2002).

But what about the creature consciousness/state consciousness distinction? We saw above that this seems to be a genuine distinction between different properties denoted by 'consciousness'. Doesn't this suggest that 'consciousness' is ambiguous, at the very least, between state and creature consciousness? Antony, like McBride, 
objects to the widespread acceptance of the state consciousness/creature consciousness distinction. First, he suggests that if creature consciousness is interpreted as something akin to 'wakefulness' then it doesn't really correspond 'to a meaning of 'consciousness' within the literature' (Antony 2001, 30). Contemporary theorists of consciousness are not trying to account for the sleeping/waking cycle. Suppose creature consciousness signifies something more substantive, something that is more closely related to notions like awareness and experience. Antony argues that this does not introduce a distinct notion of 'consciousness'. The apparent semantic variability can be explained in terms of semantic modulation relative to a core semantic base notion of consciousness. So, like McBride, he seeks to undermine the idea that the creature/state consciousness distinction specifies an ontological distinction between different kinds of property. He offers an analogy by way of clarification.

[C]onsider the word 'corrupt' in the expressions 'corrupt government' and ‘corrupt politician'. 'Corrupt' refers to distinct properties when applied to organizations and individuals no less than does 'consciousness' when applied to creatures and states. But it surely does not follow that 'corrupt' is ambiguous between "individual corruption" and "organizational corruption." A more plausible view is that 'corrupt' is univocal, and modulation is taking place, with different properties being highlighted across contexts. And so similarly with 'consciousness' vis-à-vis states and creatures. (Antony 2001, 30-31). 
Though it may not (yet) be obvious, this passage is extremely instructive. Antony's analogy involves a semantic misinterpretation. 'Corrupt' in this example is being used as an attributive adjective. In such a context it is not being used predicatively and thus does not refer to any properties at all. It is being used to restrict the reference class of the noun-phrase it modifies. So what? This may seem to be a needless, over-fussy, nit-picking point. How can this possible matter to our discussion of the ambiguity of 'consciousness'?

It is arguable (and it will be argued in a moment) that a proper understanding of the creature/state consciousness distinction requires a clear and focused understanding of the semantics of attributive adjectival modification. By engaging in a more detailed semantic, and historical, analysis of the notion of state consciousness we not only expose some of the flaws in this kind of univocalism, but we will be provided with the explicit material that we need to properly understand just why consciousness is both polysemic and ambiguous.

\section{The semantics of state consciousness}

\subsection{States of consciousness, NOT state consciousness}

There is a deep ambiguity in the notion of a conscious state and related notions like $a$ state of consciousness. A state is a mode or condition of something. Many predicative adjectives can be used to claim that some object or person is a certain way, or, as we might say, that they are in a certain state. For example:

(a1) The volcano is dormant. 
(a2) The volcano is in a dormant state.

This grammatical move is not legitimate for all predicative adjectives (e.g. 'Tom is loud'; 'Cake is tasty'). In English it may be that the shift from the predicative use of the adjective to the attributive use introduces a change in meaning (e.g., from 'Tom is terrible' to 'Tom is in a terrible state'; from 'Sue is American' to 'Sue is in an American state'). But predicative adjectives like 'swollen', 'conscious', 'alert', and 'attentive', all allow a legitimate move from predication to 'state' talk without much change in meaning.

Consider a second example.

(b1) Tom is conscious.

(b2) Tom is in a conscious state.

Even though (b2) involves talk of a conscious state, it does not introduce the notion of state consciousness as it features in contemporary philosophy of mind, for we are not predicating consciousness of the state. Tom's state is one of consciousness. But his state isn't conscious. A parallel holds for property nouns like 'condition'. To say that a person's condition is stable is to say what the condition is; it is not to predicate of the condition that it, as well as the person, is stable. Now consider a third type of example.

(a1) The volcano is dormant.

(a3) The volcano is in a state of dormancy. 
(b1) Tom is conscious.

(b3) Tom is in a state of consciousness.

Here we have formed abstract nouns from the predicate. But here dormancy is still a property of the volcano, not of the state. Similarly, consciousness is a property of Tom, not of his state. Talk of a conscious state or a state of consciousness need not bring in anything other than creature consciousness. If we unpack the notion of a conscious state in this way then the univocalist might seem to be correct: talk of states of consciousness is just a way of talking about states of creature consciousness and thus no new notion of consciousness is drawn upon her.

\subsection{The epistemic conscious/unconscious contrast}

If the notion of a conscious state is just a variant on creature consciousness predication, where does the idea that we can predicate consciousness of mental states come from? The modern notion of mental state consciousness emerges, in semantic terms at least, by way of the distinction between conscious and unconscious mental states. 'Conscious' is, etymologically, an epistemic notion (**** 2002a). The original and primary use of 'conscious' in English, from the early seventeenth century onwards, is as a predicative adjective applied to people (not mental states). It is used as a prepositional adjective ('conscious of'; 'conscious unto'; 'conscious with') to denote a person's knowledge of some matter, or to denote shared knowledge between parties. ${ }^{2}$ It is also used as part of a predicative adjectival 'that'-clause construction

\footnotetext{
2 'All that I ever did shee's conscious of, and jealous of your love unto Hermione.' William Berkeley, The lost lady: A Tragy Comedy. (London, John Colby, 1638) Act IV Scene 1. (p. 36)
} 
('S is conscious that $\left.p^{\prime}\right){ }^{3}$ At roughly the same time (early seventeenth century), we find 'conscious' being used attributively. First, in a poetic or metaphorical way to suggest that certain inanimate things share knowledge with human beings. ${ }^{4}$ Second, by way of emphasising the fact that a subject, or some subject-like entity (the soul, one's 'heart') knows something, or is capable of knowledge. ${ }^{5}$ By the eighteenth century the attributive use of 'conscious' has become common in English literature, modifying mental terms like belief, desire, hope and will. But we do not find the predication of 'consciousness' of mental states.

So where does the notion of state consciousness come from then? Because 'consciousness' is an epistemic notion, it was readily adopted as a technical term for the special kind of knowledge that each of us has of our own minds. ${ }^{6}$ 'Consciousness' becomes synonymous with 'self-knowledge', and specifies a relational property between a subject and her mental states. Consciousness involves a kind of higher-order knowledge of one's first-order mental states. In the late nineteenth century psychologists started to ascribe intentional states that seemed not to be knowable by their subjects in a direct first-personal way (****, 2000b). This relational higher-order epistemic notion of consciousness was re-deployed to mark a contrast within the class of mental states. Conscious mental states are known by their

\footnotetext{
3 'Because they play the Fool, conscious that it will please.' George Farquhar, Love and a bottle. (London: Richard Standfast, 1699) Act IV (p. 43).

${ }^{4}$ 'Yet I am mad, I rave and tear my self, traverse my guilty chamber in a disorder'd, but a soft confusion; and often opening the conscious curtains, survey the print where thou and I were last night laid.' Aphra Behn, Love-Letters Between a Noble-Man And his Sister, (1684), 'To Philander, After the Happy Night,' Part 1

5 'Then Feliche stabd (Whose sinking thought frighted my conscious hart) and laid by Mellida, to stop the match,' John Marston,, ANTONIO'S Reuenge. The second part of the Historie of Antonio and Mellida. (1602); 'Euen such would be your life, whose guilt each houre would strike your conscious soule with terrors' Robert Daborne, A Christian turn'd Turke. OR, The Tragicall Liues and Deaths of the two Famous Pyrates, WARD and DANSIKER. (1612) (Act 1, Scene 4).

${ }^{6}$ For example Locke held that 'Consciousness is the perception of what passes in a Man's own mind' (Locke 1959 [1690] II i 9), whilst Reid observed that 'consciousness' signifies 'that immediate knowledge which we have of our present thoughts and purposes, and, in general, of all the present operations of our minds' (Reid 1785, I.i).
} 
subject in a direct first-personal way, whilst unconscious ones are not. This same notion of consciousness underpins the distinction between conscious and unconscious mentality in psychoanalytic theory, and also, at least in part, in cognitive science (e.g., Chomsky's unconscious knowledge of grammar (Chomsky 1980)). It has also resurfaced in theorising about consciousness in higher-order thought theories of mental state consciousness (Rosenthal 1997; Lycan 1996; Carruthers 1998).

\subsection{From classification to predication: the emergence of state consciousness}

The distinction between conscious and unconscious mental states is a classificatory one. When we talk of a conscious belief, a conscious sensation, a conscious desire, a conscious mental state, 'conscious' is being used as an attributive adjective. Attributive uses of adjectives, as was noted above with reference to Antony's 'corrupt politician' example, effect a restriction upon, or a narrowing of, the reference class of the noun-phrase that they modify: e.g., rural policeman; dental floss; dental surgeon; criminal lawyer (Bolinger 1967). Predicative adjectival use, by way of contrast, allows the speaker to state something about an object. The semantic notion of satisfaction, introduced by Tarski (1944) provides a tidy way of spelling out the semantics of predicates, including predicative adjectives. In Tarski's schema, an object satisfies a predicate ' $F$ ' if and only if that object is $F$. This works fine for 'red', 'ugly', 'bigger than the Eiffel Tower' and so on. This kind of semantic analysis just doesn’t work for attributive adjectival modification. Suppose we try to substitute 'dental' for ' $F$ ' in Tarski's semantic schema. First we fail to get a well-formed expression (' $\mathrm{O}$ is dental') on the right-hand side of the 'if and only if' (signalling the non-predicating nature of dental). But, second, such a schema fails to take account of 
the fact that 'dental' seems to vary in its meaning depending upon the noun-phrase modified. A person is a dental surgeon in virtue of being a doctor who operates on teeth. But pieces of string are dental floss in virtue of their aptness for use in cleaning between teeth. On the other hand, a space is a dental cavity in virtue of being located within a tooth. An appointment is a dental appointment in virtue of being made with a party who operates upon or examines teeth. There is semantic variation here, but when we spell out the meaning in each case, there is a constant semantic element, an implicit reference to teeth. Let us follow linguists in referring to this common feature as the semantic base notion for the attributive adjective (Aarts \& Calbert 1979).

In order to use Tarski's schema to spell out the semantics of nonpredicating adjectives we need to have predication on both sides. We can talk of an object's being a dental drill, of a person being a dental surgeon and so on. This secures predication on the left-hand side. As for giving the semantics in terms of satisfaction we can use Aarts and Calbert's concept of a predicational relator to denote the various ways in which an attributive adjective relates to a single base semantic notion depending on the noun-phrase modified (Aarts \& Calbert 1979). In our example above, the base semantic notion is that of teeth whilst the predicational relators include: ‘. . operates on . .’; ‘ . . is used to clean . .’; ‘ . . is within . .’. A drill is a dental drill if and only if it used to operate on teeth. A person will only understand what a dental drill is, only if (a) they know what the semantic base notion is and (b) know the appropriate predicational relator (e.g., 'dental drill' might, in certain contexts, refer to a drill made of teeth). Whilst attributive adjectival modification exhibits a puzzling semantic variability, we explain that variability by appeal to the variety of predicational relators whilst establishing an underlying semantic unity via the single semantic base notion. Dental things are all bound up with teeth in some way or other. 
We are now in a position to see how the contemporary notion of mental state consciousness emerges out of a long process of abstraction and semantic meandering. We begin with the everyday predicative use of 'is conscious' as an epistemic term. Philosophers co-opt 'consciousness' as a technical term for knowledge of mind. Psychologists introduce the classificatory distinction between conscious and unconscious mental states, drawing upon the higher-order epistemic notion of consciousness. The only predicative use of 'conscious' so far is with regard to people or creatures. Psychoanalytic theorists needed some way of talking about the changing status of repressed mental material and, with these concerns in mind, talk of repressed ideas becoming conscious, being conscious, failing to be conscious and so on, becomes pertinent (and saves the theorist from using long-winded locutions like 'becoming available to first-person self-knowledge'). The key point in the emergence of a notion of state consciousness is the introduction of a purely predicative use of 'conscious' (in the epistemic sense) with regard to mental states. Once we have the predicative notion in play we can then, as we saw above, form a de-adjectival abstract noun 'consciousness'. But we already have a notion of consciousness in play (i.e., epistemic consciousness as predicated of people). In order to avoid conflation and confusion we introduce the notion of state consciousness as a label for the epistemic property (being known in a first-personal way) that certain mental states have.

State consciousness is thus quite unlike the notion of a state of consciousness. The latter is a way of talking about creature consciousness, the former is a way of talking about certain (epistemic) features of mental states. The state consciousness/creature consciousness distinction is as real as the distinction between (a) being a knower; (b) being known. 


\section{Some more strands of consciousness}

Though there is something in common, semantically speaking, between state consciousness and creature consciousness, they are distinct phenomena and, given that they both are referred to as species of consciousness it seems that there is a standing risk of conflating them (indeed, both Antony and McBride's 'grammatical' objections seem to reflect an underlying conflation of state consciousness with the notion of a state of consciousness, and thus adds further support to the thesis that 'consciousness' is ambiguous). We could, at this point, stop and address the question whether the state/creature consciousness distinction really counts as an instance of polsyemy and ambiguity. But we have barely scratched the surface of the polysemy of 'consciousness'. Matters are much, much worse for the univocalist who holds that we have a common, shared understanding of what 'consciousness' refers to.

\subsection{First-order epistemic consciousness}

We have seen that the original semantic base notion for 'conscious mental state' is a notion of creature consciousness: the epistemic notion of someone being conscious of some object or fact. This base notion is a relational one (a subject's knowing of something). Whilst mental states are the objects of consciousness (in Locke's sense) it is also true that knowledge is a relation that is instituted via mental states. We are conscious of nonmental objects and states of affairs. A conscious mental state can be viewed as one that we are aware of something through. This provides us with an alternative, but still epistemic, notion of mental state consciousness, one that is distinct from the higher-order conception. In contemporary thought, Dretske draws 
upon this first-order epistemic notion of consciousness when he states that 'experiences and beliefs are conscious, not because you are conscious of them, but because, so to speak, you are conscious with them' (Dretske 1993, 280). A conscious belief, in Dretske’s view 'is a representation that makes one conscious of the fact (that p) that it is a belief about' (Dretske 1993, 280).

The epistemic semantic basis of 'consciousness' makes it fit to do duty as a technical term for our perception and knowledge of the world, or as a technical term for our knowledge of our own minds. Relative to the single semantic base notion of a subject's being conscious of something we can identify two different, equally legitimate, predicational relators for 'conscious mental state':

(a) A mental state is a conscious mental state if and only if it is an object of knowledge (of a certain kind).

(b) A mental state is a conscious mental state if and only if it is a state of knowing of something or, a state via which one knows of something.

So far we have been focusing on semantic variation relative to a single semantic base notion (epistemic consciousness). In some cases there is potentially more than one semantic base notion for a single lexical term used attributively. Language is a dynamic, fluid affair. Some terms come to be used in a new way, even whilst the older use remains. Prior to 1950, 'gay' used attributively had a meaning quite different to its contemporary one. When Wordsworth talks of a 'choir of gay companions' the semantic base notion is not the contemporary one. ${ }^{7}$ Here, unlike the 'metal box' example, the risk of conflation is at the level of the semantic base notion. 
We find the same kind of semantic shift, at the level of semantic base notion, with regard to 'conscious'.

\subsection{Experiential or phenomenal consciousness}

In our story above, 'consciousness' is an epistemic term of everyday English that has been put to work in various philosophical and psychological contexts. But 'consciousness' has also been used, and continues to be used, in a nonepistemic way. 'Consciousness' in the traditional philosophical epistemic sense is bound up with knowledge of mind. We know of our mental states in a direct first-personal way. When we reflect upon the nature of our own minds, especially when we reflect upon the nature of our current experience, we seem to identify something determinate: states that are like something independently of our knowing of them to so (pace Dennett 1992). Our waking mental life seems to involve a stream of events that have a distinctive subjective ontological character (e.g., you don't feel my pains). 'Consciousness' has long been used as a label for the subjective ontological features that seem to be both independent of, and the basis of, our knowledge of mind. Rather than viewing 'consciousness' as an abstract epistemic noun, 'consciousness’ becomes the label of something more concrete, 'consciousness' is viewed as denoting some kind of subjective ontological phenomena, something that can be described using spatial metaphors like 'stream' or 'field'.

Almost two centuries ago, William Hamilton, in his Lectures on Metaphysics delivered in 1836, outlined a dispute between philosophers who 'say that consciousness is a knowledge' and 'many others' who 'have defined consciousness

\footnotetext{
${ }^{7}$ William Wordsworth, The Excursion 'Despondency' 'In the devotedness of youthful love, preferring
} 
as a feeling' (Hamilton 1859, Vol 1., 191). Forty years later, Alexander Bain in cataloguing the 'various significations' of the term 'consciousness' argued against Hamilton that 'the knowledge or attention, although an accompaniment of the state, is not its foundation' (Bain 1879, 94). Half a century after that we find McDougall (1923) bemoaning the fact that “"consciousness” is generally taken to be almost, if not quite, synonymous with “experience”” (McDougall 1923, 16). McDougall suggests that “"consciousness," if it is used at all, should be used to mean "the act of knowing or thinking of things"' and that "the word "conscience" would have been a better word than “consciousness” for psychological purposes' (1923, 16). And, in recent years we find Ned Block arguing at length that cognitive theorists conflate an experiential, non-representational (and thus nonepistemic) notion of consciousness (phenomenal consciousness) with another epistemic notion of consciousness (awareness, or access-consciousness) (Block 1995; 1997).

We have not space to explore this rich historical (and contemporary) debate here. For our purposes what matters is that we seem to be able to (fairly readily) identify a second, nonepistemic semantic base notion for 'consciousness' and 'conscious mental state'. The semantic base notion, as with the epistemic notions discussed above, is a notion of creature consciousness (its being like something for a creature). The predicational relator is that of making a contribution to what it is like for that creature. Or, to put it in more familiar terms:

(c) A mental state is a conscious mental state if and only if it is like something for a subject to be in it, or have it.

me to parents, and the choir of gay companions, to the natal roof' (lines 506-7) 
Earlier we construed the state/creature consciousness distinction in epistemic terms. But we can also construe it in experiential, or phenomenal, terms: creature consciousness is a matter of its being like something for subject; state consciousness is constituted by state's making a contribution to what it is like for that subject. Given that all state consciousness, creature consciousness, in its epistemic and experiential guises might all casually be referred to using 'consciousness' it seems inescapable that 'consciousness' is deeply polysemic and ambiguous. ${ }^{8}$

\section{Five problems for univocalism}

Our analysis in terms of predicational relators and semantic bases has a good deal in common with Antony’s ‘semantic modulation' account. So far it seems to differ in at least the following two respects. First, we have accepted the reality of the distinction between creature consciousness and state consciousness. Second, we have identified two distinct semantic base notions for consciousness (epistemic, experiential). Third, we have a more subtle and articulate way of showing why different notions of consciousness should arise from these semantic base notions via different predicational relators.

One line of response open to the univocalist is to stress, as Antony does, that the core notion of consciousness is a complex, multi-faceted one (Antony 2001, 29). On this univocalist view our conception of mind supports what we might call a single but knotty conception of consciousness. In different contexts different strands of the knot of consciousness are brought to the fore. We can explain away the polysemy of

\footnotetext{
${ }^{8}$ Matters become even more complex if we view consciousness as a dispositional notion: e.g., a conscious belief is one that is disposed to be conscious (this could mean, one that is disposed to be an
} 
'consciousness' in terms of semantic modulation relative to the single knot of consciousness. So, even though we seem to have identified a deep ambiguity in the notion of consciousness, Antony might claim that our semantic analysis hasn't gone deep enough. Epistemic and experiential consciousness are really just different facets of, a more fundamental complex phenomenon and it is this complex phenomenon that is the proper semantic core notion for 'consciousness'.

There is something right about this (and something problematic, as we shall see). Our perceptual experience of the world is constituted by states that exhibit all three of the species of state consciousness introduced above and our status as conscious subjects is interdependent with the conscious status of our mental states. We are conscious of the world via our perceptual events; it is like something to be in, or be the subject of, such events; we know of such events in a direct first-personal way. Perceptual events exhibit phenomenal consciousness and both kinds of epistemic consciousness noted above. The univocalist will, quite rightly, stress that there is a sense in which all these elements seem to be unified together in a single experiential point of view. Even if all this is true, however, it does not secure univocalism. Here are five reasons why not.

\subsection{The consensus problem}

Antony's univocalism rests upon the observation that 'there is a general sense of 'consciousness' that enjoys widespread use' (2001, 25). Antony alludes to the appearance of the term 'consciousness' in the title of various journals and books and cites works by Baars, Crick and Koch, and Chalmers. But, unfortunately for Antony, 
it is not at all clear that these theorists view consciousness in the same way at all. Crick and Koch ask 'When is an animal conscious?’ (Crick and Koch 1997, 279), they are thus concerned with the question of what it is for a brain or a creature to be conscious. Baars, by way of contrast, very clearly stresses that he is interested in the contrast between conscious and unconscious mental states and processes (Baars 1988, 70). Chalmers is keen to narrow 'consciousness' to experiential consciousness and, like McBride above, argues that 'what is central to consciousness . . . is experience' (Chalmers 1996, 4).

There is a troubling line of inference here. Antony holds that 'consciousness' picks out the complex knot of experience, self-knowledge, intentionality and so on. It is true that the various theorists cited by Antony all write upon one or more of these phenomena, but that does not mean that they all accept that 'consciousness' picks out one and the same knot: what seems more plausible is that they pick out one or more strands of that knot. What Antony needs to establish his non-ambiguity claim is a widespread acceptance of the same complex of features as the referent of 'consciousness'. We cannot establish this in an aggregative way. For example, suppose I claim that the common, accepted referent of 'consciousness' is a complex phenomenon exhibiting properties F,G,H, I, J. If one theorist takes 'consciousness' to pick out F, G, H; another, G, H, I, and the third takes it to pick out $H, I, J$, then it is true that all are agreed that 'consciousness' is a complex phenomena, but they disagree as to which complex phenomenon it is. I cannot aggregate their particular commitments into a commitment to the compound phenomenon that $I$ take 'consciousness' to refer to.

perhaps one that is disposed to be like something for the subject). 


\subsection{The unwittingness problem}

If there really is a shared commitment to viewing 'consciousness' as a particular complex phenomenon, why is there widespread, ongoing, discussion about the many meanings of 'consciousness'? Why is there a widespread practice of explicitly classifying 'consciousness' into its sub-variants? Do we lack knowledge of what we really mean when we talk about 'consciousness'?

It seems to be precisely because we know that 'consciousness' is ambiguous that we engage in all this sub-classification of different notions of consciousness. The univocalist, one assumes, will argue that this is some kind of error on our part. But this is no good. The univocalist case rests upon a de facto shared conception of 'consciousness' as the basis for rejecting the ambiguity view. What the univocalist needs is to establish a prior common acceptance of a single notion of consciousness as the semantic core and, if there is widespread acceptance of ambiguity, the univocalist's claim of a prior consensus is seriously undermined.

\subsection{The consciousness-conferring properties problem}

Suppose we allow Antony's claim that there is some compound general sense of 'consciousness' that includes epistemic and experiential variants of consciousness. Suppose, for the sake of argument, that people agree about the extension of 'consciousness', that it picks out just one specific complex of properties. We cannot infer from the fact that there is agreement about the extension of 'consciousness' that theorists thereby mean the same thing by 'consciousness'. For example, suppose Tom uses the predicative adjective 'squiffy' to denote creatures with hearts and Sue 
uses 'squiffy' to denote creatures with kidneys. Tom and Sue agree about which creatures are squiffy, but this does not mean that squiffiness is not an ambiguous concept. Tom and Sue differ with regard to which properties are the squiffinessconferring ones, and should they encounter-or perhaps imagine, via thought experiments-unusual cases where they encounter a creature with a heart but without kidneys, the differences in their conception of squiffiness will come to the fore.

The same point applies in theorising about consciousness. In contemporary writing on the mind experiential consciousness has come to the fore as the favoured consciousness-conferring property. Intentional features of mind get to be conscious insofar as they exhibit phenomenal or experiential properties. Eric Lormand, for example, argues that 'phenomenal consciousness is the most basic kind of consciousness' (Lormand 1996, 255). Burge insists that 'phenomenal consciousness is the core notion' of consciousness. (Burge 1997, 429). Marcel avows that 'Phenomenal experience is [. . .] the raison d'etre of the concept of consciousness' (Marcel 1988, 128).

But not everyone agrees. Lycan, by way of contrast, informs us: 'I cannot myself hear a natural sense of the phrase 'conscious state' other than as meaning 'state one is conscious of being in'” (Lycan 1996, 25). Other higher-order though theorists agree with Lycan. Lycan and Burge might agree about the extension of 'consciousness' but this is only because in normal human experience the candidate consciousness-conferring properties (i.e., those favoured by different thinkers) tend to be co-instantiated. The states that are like something to be in are also states that we know of first-personally.

When we move away from the paradigm case of human perceptual experience, differences as to which properties are the consciousness-conferring ones come to the 
fore. For example, when we think of animal consciousness, Burge and Marcel might be quite happy to allow a bat to have consciousness even without the capacity for self-knowledge or higher-order representation. For Lycan, by way of contrast, this is incoherent. Working in the other direction, Lycan is quite happy to allow that pocket calculators and computers might be conscious insofar as they instantiate higher-order monitoring relations even if it is not like anything for the calculator. For those who prioritise phenomenal consciousness, this seems entirely misguided.

\subsection{The differential treatment problem}

Part of the intuitive support for univocalism comes from the fact that our waking experiential life typically co-instantiates the various phenomena that have come to be called 'consciousness'. This might make it seem that we have some tacit idea of 'consciousness' as this complex of co-instantiated properties. One problem here is that our contemporary metaphysics of mind treats these various facets of our experiential life differentially. Contemporary functionalists and cognitive theorists view mental states as functional states and intentional properties as causal relational properties. The key point here is that epistemic relational properties like awareness and self-knowledge seem to be more readily explicable in functional causal terms than putative nonrelational intrinsic properties like qualia (Block 1978; Levine 2001; **** 2002c). From the point of view of contemporary functionalism one of the strands of consciousness is viewed as being fundamentally more problematic than the others (**** 2002a). This has an effect upon how theorists use the term 'consciousness'. There is a tendency to use the term 'consciousness' as shorthand for 'those putatively non-representational properties that functionalism cannot deal with'. 
'Consciousness' gets to be associated with phrases like 'the problem of consciousness'. The problem of consciousness is prised apart from the problem of representational mind, and of self-representation. Because we use our technical philosophical language to pick out features of concern to us, the extension of 'consciousness' in a lot of contemporary functionalist writing is narrowed to experience (as we saw above in the remarks from Lormand, Marcel, Chalmers and Burge). The traditional Lockean epistemic conception is kept on the go by higherorder representation theorists. Once again, when we examine the conceptual commitments of current theory, we find polysemy and ambiguity.

\subsection{Consciousness-independence and the state consciousness problem}

Functionalism and causal-representational theories provide contemporary theorising with a consciousness-independent conception of mind in both the epistemic and metaphysical senses of 'consciousness' (Searle 1992, 10; McGinn 1991; **** 2002c). That is, there is no assumption that mental states, qua mental, must be known by their subjects in a first-person way; no assumption that all representational states are states via which some subject is conscious of something; nor is it assumed that it must be like something for a subject to have a mental state. Functionalists can conceive of consciousness as a property that mental states have because they believe that mentality is something more fundamental than conscious mentality (be it in the epistemic, or in the experiential sense).

John Searle, a vocal anti-functionalist, cannot conceive of consciousness in this way. Consciousness cannot be a property that some mental states have, and that others lack, because 'consciousness', as used by Searle, denotes the subjective 
ontological medium of mind (Searle's notion of a unconscious state is of a brain state that is disposed to give rise to conscious mentality (Searle 1992)). For Searle, consciousness is not a property of mental states, mental states are determinations, or modifications of the 'field' of consciousness (Searle 1999, 82). Consciousness is always creature consciousness for Searle: "What I mean by “consciousness” can best be illustrated by examples. When I wake up from a dreamless sleep. I enter a state of consciousness, a state that continues as long as I am awake' (Searle 1992, 84).

Because theorists differ with regard to the question of how consciousness (in its various guises) relates to mentality, 'consciousness' cannot be used in the same way by all theorists. It is thus hard to see how the univocalist can claim that there is an underlying conception of consciousness that is shared by contemporary theorists.

\section{Conclusion}

'Consciousness' is both polysemic and ambiguous. McBride and Antony’s arguments do not show otherwise. But the analysis offered here does not just play a negative role in undermining the case for univocalism about 'consciousness'. It plays a positive role too. First, it lets us see just why 'consciousness' means the many things that it does. Our analysis explains why 'consciousness' is polysemic and ambiguous. 'Consciousness' and 'conscious' have been to work in various metaphysical, philosophical and explanatory contexts. The most substantive metonymic shift is from the traditional epistemic notion of consciousness to the experiential notion. A second source of the polysemic nature of 'consciousness' is the shift from using 'conscious' predicatively of human beings to using it attributively with regard to mental states. This shift began with the new practice of making explanatory appeal to 
(epistemically) unconscious mental states and has now been firmly entrenched thanks to the ascendancy of functionalism and causal-representational theories of mind.

Second, by laying stress on the fact that the various species of consciousness tend to be co-instantiated the account here alerts us to the difficulty of achieving clarity in this area. Different theorists may agree about the extension of 'consciousness' for very different reasons. We need to be alert to the distinction between an extensional characterisation of 'consciousness' on the one hand and, on the other, a characterisation in terms of finely-tuned consciousness-conferring properties.

Third, the abstract semantic analysis offered above allows us to clearly identify some of the relationships amongst various notions of consciousness. It reveals just where we need to keep notions distinct (e.g., epistemic versus experiential consciousness; state versus creature consciousness) and where we do not (creature consciousness versus states of consciousness). This points us towards the formulation of a shared technical vocabulary. There is, I take it, nothing wrong with the introduction of technical language provided that the technical terms are used in a uniform way. What we need to do is to rid ourselves of the risk of conflation, not give up our theorizing about self-knowledge, awareness of the world and the nature of subjective experience. We cannot rule out a priori the possibility that, if good practice demands it, the best solution may be to cease to use 'consciousness' in our theorising about mind (even if we continue to use the term in our historical discourse).

The univocalist view, by way of contrast, poses a real danger. If we assume that we all know what we mean when we talk about 'consciousness' and 'conscious mental states' then we are apt to become complacent. We will shy away from trying 
to clarify what we mean, and will resist the temptation to introduce explicit technical vocabulary to do the work of disambiguating 'consciousness'. This may make for seemingly clearer technical exposition (and it may save a few trees en route), but the downside is that the ever-spreading thicket that is the philosophy of consciousness is likely to become so tangled as to be completely impenetrable. We need to face up to the ambiguity of 'consciousness' and to deal with it head on as best we can by clarifying what we mean when we talk about consciousness. My hope is that the analysis here establishes a justification for attempting such a clarification and also provides an abstract framework that might help achieve it.

\section{References}

[references to author's own work deleted]

Aarts J. \& Calbert J. (1979) Metaphor and Non-Metaphor: The Semantics of Adjective-Noun Combinations. Tubingen: Max Niemeyer Verlag.

Allport, A. (1988). 'What Concept of Consciousness', in Marcel and Bisiach (eds), 159182.

Antony, M.V. (2001) 'Is 'Consciousness' Ambiguous?' Journal of Consciousness Studies 8, 19-44)

. (2002) 'Concepts of consciousness, kinds of consciousness, meanings of 'consciousness' , Philosophical Studies 109, 1-16

Baars, B. J. (1988). A Cognitive Theory of Consciousness. Cambridge: Cambridge University Press.

Bain, A. (1879). Mental and Moral Science Vol 1, 3rd ed. London: Longmans, Green \& Co.

Block, N. (1978). 'Troubles with functionalism', in N. Block (ed.) Readings in the Philosophy of Psychology, 2 vols. Cambridge, MA: Harvard University Press.

. (1995). 'On a confusion about a function of consciousness', Behavioral and Brain Sciences, 18, 227- 287.

. (1997). 'On a confusion about a function of consciousness', (revised version) in Block, Flanagan and Güzeldere 1997, 375-416

Block, N., Flanagan, O. and Güzeldere, G., eds, (1997). The Nature of Consciousness: Philosophical Debates. Cambridge MA: MIT Press.

Bolinger, D. (1967) ‘Adjectives in English: Attribution and Predication’ Lingua 18. 134

Burge, T. (1997). 'Two Kinds of Consciousness', in Block, Flanagan, and Güzeldere 1997, 427-433

Burt, C. (1962). 'The concept of consciousness' British Journal of Psychology 53:229-42. 
Carruthers, P. (1998). Natural theories of consciousness' European Journal of Philosophy, 6 1998, 203-222.

Chalmers, D. (1996). The Conscious Mind. Oxford: Oxford University Press.

Chomsky, N. (1980). Rules and Representations. Oxford: Blackwell.

Crick, F., \& Koch, C. (1990). 'Towards a Neurobiological Theory of Consciousness.' in in Block, Flanagan and Güzeldere 1997, 278-292

Cruse, D. A. (1986). Lexical Semantics, Cambridge: Cambridge University Press.

Dennett, D. (1992). Consciousness Explained. London: Penguin Books.

Dretske, F. (1993). 'Conscious Experience', Mind, 102, 263-283.

Hamilton, W. (1859) [1836]. Lectures on Metaphysics and Logic, 4 vols. Edinburgh: William Blackwood

Levine, J. (2001). Purple Haze: The Puzzle of Consciousness. Oxford: OUP

Lewis, C.S. (1960). Studies in Words. Cambridge: CUP

Locke, J. (1959) [1690]. An Essay Concerning Human Understanding collated by A.C. Fraser. New York: Dover.

Lormand, E. (1996). 'Nonphenomenal Consciousness', Noûs, 30, 242-261.

Lycan, W.G. (1996). Consciousness and Experience. Cambridge MA.: MIT Press.

Marcel, A. (1988). 'Phenomenal experience and functionalism' in Marcel and Bisiach 1988, 121-158

Marcel A., \& E. Bisiach (eds) (1988). Consciousness in Contemporary Science. Oxford, Clarendon.

McBride, R. (1999) 'Consciousness and the state/transitive/creature distinction' Philosophical Psychology 12, 181-196

McDougall, W. (1923). An Outline of Psychology London: Methuen.

McGinn, C. (1991) The Problem of Consciousness. Oxford: Blackwell..

Natsoulas, T. (1978). 'Consciousness,' American Psychologist, 906-914

Nelkin, N. (1993) 'What is consciousness?' Philosophy of Science 60, 419-34

Reid, T. (1785). Essays on the Intellectual Powers of Man

Rosenthal, D.M. (1997). 'A Theory of Consciousness', in Block, Flanagan and Güzeldere, 729-753.

Searle, J. (1992). The Rediscovery of the Mind. Cambridge Mass.: MIT Press. . (1999) Mind, Language and Society. London: Weidenfeld \& Nicolson

Tarski, A. (1944) 'The semantic conception of truth' Philosophy and Phenomenological Research 4, 341-75

Tye, M. (1996). 'A Representational Theory of Pains and Their Phenomenal Character', Philosophical Perspectives 9, 223-239.

Van Gulick, R. (1996). 'What Would Count as Explaining Consciousness', in T. Metzinger, (Ed.) Conscious Experience Exeter: Imprint Academic, pp. 61-80

Wilkes, K.V. (1988) ‘- yishì, duh, um and consciousness’ in Marcel and Bisiach (eds) 16-41

Wilkes, K. V. (1996). 'Losing Consciousness', in T. Metzinger (ed.) Conscious Experience Exeter: Imprint Academic. 97-106. 